\title{
ALLOGENEIC HEMATOPOIETIC STEM CELL TRANSPLANTATION IN FANCONI ANEMIA; A SINGLE CENTRE EXPERIENCE
}

\author{
Tariq Azam Khattak, Muhammad Farhan, Tariq Ghafoor, Tariq Mahmood Satti, Qamar Un Nisa Chaudhry, \\ Mehreen Ali Khan \\ Armed Forces Bone Marrow Transplant Center/National University of Medical Sciences (NUMS) Rawalpindi Pakistan
}

\begin{abstract}
Objective: To determine the treatment outcome of Hematopoietic stem cell transplantation in Fanconi Anemia. Study Design: Case series.

Place and Duration of Study: Armed Forces Bone Marrow Transplant Center, Rawalpindi, from Jan 2001 to Jun 2018.

Methodology: Data of all Fanconi anemia patients who had fully HLA matched bone marrow transplant during this period was analysed for variables affecting the outcome in terms of overall survival. Those fanconi anemia patients who had myelodysplastic changes or acute myeloid leukemia were excluded.

Results: Total 27 patients underwent fully HLA matched allogeneic bone marrow transplant for Fanconi Anemia. Mean age of patients at transplant was $12.12 \pm 5.16$ years. All patients at transplant were in aplastic phase. Conditioning was done with fludarabine $120 \mathrm{mg} / \mathrm{m}^{2}$, ATG $20 \mathrm{mg} / \mathrm{kg}$ and Cyclophosphamide at a dose of 20-40 $\mathrm{mg} / \mathrm{kg}$. Mean time to neutrophil engraftment was $12.3 \pm 2.92$ days and for platelets $20 \pm 10.3$ days. Major posttransplant complications were neutropenic fever in $26(96 \%)$, hypertension in 18 (66.6\%), mucositis in $12(44.4 \%)$, azotaemia in $8(29.6 \%)$, gut toxicity in $7(25.9 \%)$ and haemorrhagic cystitis in $5(18.5 \%)$ patients. Four patients $(14.8 \%)$ had acute graft versus host disease while 7 (26\%) patients had chronic GVHD. Overall survival at 6 months, 1,5 and 8 years was $67 \%, 63 \%, 59 \%$ and $55 \%$ respectively. While overall survival in patients transplanted at younger age (<11 years) was $81.8 \%$ compared to $37.5 \%$ in older age group (>11years) and was statistically significant $(p$-value $=0.03)$.

Conclusion: Our study demonstrated survival difference in Fanconi anaemia patients when transplanted at younger age and conditioning with cyclophosphamide $30 \mathrm{mg} / \mathrm{kg}$, fludarabine $120 \mathrm{mg} / \mathrm{m}^{2}$ and thymoglobulin $10 \mathrm{mg} / \mathrm{kg}$ as an acceptable conditioning protocol.
\end{abstract}

Keywords: Fanconi anaemia, Graft versus host disease, Hematopoietic stem cell transplant.

This is an Open Access article distributed under the terms of the Creative Commons Attribution License (http://creativecommons.org/licenses/by/4.0), which permits unrestricted use, distribution, and reproduction in any medium, provided the original work is properly cited.

\section{INTRODUCTION}

Fanconi Anemia is a rare bone marrow failure syndrome characterized by congenital malformations, progressive cytopenias with malignant predisposition 1 . It was first described by Swiss pediatrician Guido Fanconi in 1927. The incidence of FA is around 3 per million with a carrier frequency of 1 in $300^{2}$. It is reported in all races and ethnic groups with highest incidence in some Spanish populations, with carrier frequency of 1 in $70^{3}$. Individuals with birth defects are diagnosed at younger ages than those without birth defects. Genetic mutations in specific genes results in Fanconi anemia. Protein produced by

Correspondence: Dr Tariq Azam Khattak, Asst Prof, Armed Forces Bone Marrow Transplant Center, Rawalpindi, Pakistan Received: 31 Jul 2019; revised received: 01 Sep 2019; accepted: 05 Sep 2019 these genes constitutes Fanconi anemia pathway, essential for repair of damaged DNA especially Interstrand Cross Links (ICLs) resulting in buildup of ICLs when FA pathway is non-functional. The ICLs results in abnormal cell death or uncontrolled cell growth particularly in rapidly dividing cells of bone marrow and developing fetus causing congenital malformations, bone marrow failure and pre-disposition to malig-nancies 4 .

Clinical presentation of FA is heterogeneous. One third patients have no physical features suggestive of FA thus making it mandatory to screen all patients with bone marrow failure. Cardinal physical findings are absent or hypoplastic thumb, microcephaly, skin pigmentation and peculiar fanconi facies 5 . Majority of patients develops pancytopenia in the first decade of life 
with cumulative incidence of BMF around 90\% by 40 years of age $^{6}$. It can present with MDS converting into Acute myeloid leukemia or with leukemia as initial manifestation ${ }^{7}$. There are increased chances of developing solid tumors, especially in patient who underwent allogeneic bone marrow transplant necessitating surveillance in all transplant recipients ${ }^{8}$.

The screening test for FA is chromosomal breakage analysis in which cultured T-lymphocytes of patient are exposed to mitogen and DNA clastogenic agent as Diepoxybutane (DEB) or mitomycin C (MMC), while confirmatory test is genetic analysis for the underlying mutation. Fanconi screening should be performed in individuals having siblings with FA, characteristic birth defects suggestive of Fanconi, all patients with Aplastic anemia, Primary MDS or AML at a young age or cancers typical of FA at younger age ${ }^{9}$. Fanconi anemia patients require regular monitoring for bone marrow failure and malignancy with serial blood counts and periodic cytogenetic analysis. Anabolic steroids result in transient hematological response with potential risk of side effects ${ }^{10}$. Hematopoietic stem cell transplantation (HSCT) is the only curative option for BMF. It has evolved overtime with improved outcome due to transplant at younger age and reduction in drug doses particularly cyclophosphamide ${ }^{11}$.

Armed Forces Bone marrow transplant is a leading institute of Pakistan, performing bone marrow transplant for various benign and malignant hematological disorders since its establishment in 2001 including Fanconi anemia. We wanted to share our center experience of post-transplant outcomes in FA in terms of overall survival and post-HSCT acute and long-term complications in this study.

\section{METHODOLOGY}

This case series study included all patients who underwent hematopoietic stem cell transplant for Fanconi Anemia at AFBMTC, form Jan 2001 to Jun 2018. FA patients who transformed into AML or MDS were excluded from the study. Study data included age of patients, gender, age at diagnosis, age at transplant (age $<11$ years versus age $>11$ years), donor characteristics, source of stem cells, days to neutrophils and platelet engraftment, post-transplant acute and chronic complications, causes of mortality and overall survival. Informed consent was obtained from the participants and approval was sought from Institutional review board (IRB-007/AFBMTC/ Approval/2018).

Diagnosis of fanconi anemia was confirmed by chromosomal breakage analysis. Genetic mutation analysis was not performed. All patients had bone marrow failure with transfusion dependency at time of transplant. Prior to admission in transplant ward, all patients were in stable clinical condition with no active bacterial, viral or fungal infection.

All patients were treated in a single room with high-efficiency particulate air (HEPA) filters and infectious control guidelines were followed. Prophylaxis against viral, fungal and Pneumocystis jiroveci pneumonia infection was given. Blood products usedwere leukodepleted, irradiated and viral screened. Cytomegalovirus reactivation was monitored by weekly/fortnightly quantitative PCR from day +30 till 3 months posttransplant.

Conditioning chemotherapy comprised of Fludarabine at $120 \mathrm{mg} / \mathrm{m}^{2}$, Thymoglobulin $10 \mathrm{mg}$ $/ \mathrm{kg}$ and cyclophosphamide at $20-40 \mathrm{mg} / \mathrm{kg}$ in four equal divided doses as shown in fig-1.

Neutrophil engraftment was defined as absolute neutrophil count $\geq 0.5 \times 10^{9} / \mathrm{L}$ for 3 consecutive days while platelet engraftment as platelet count $\geq 20 \times 10^{9} / \mathrm{L}$ without platelet transfusion for 1 week. Primary graft failure was defined as failure to achieve an ANC of $0.5 \times 10^{9} / \mathrm{L}$ by day 28 and secondary graft failure as ANC <0.5 $\times 10^{9} / \mathrm{L}$ or donor chimerism less than $10 \%$ by molecular analysis in patients who previously achieved an ANC of $0.5 \times 10^{9} / \mathrm{L}$. Overall survival (OS) was taken as time from date of HSCT to last follow up. We graded Acute GVHD as per modified Glucksberg system ${ }^{12}$ while National Institute of 
Health Consensus Conference guidelines were used to classify Chronic GVHD ${ }^{13}$.

SPSS version 25 was used for calculation of frequency, percentages, mean, median and Standard deviation (SD). Survival analysis was performed with Kaplan Meierestimator. A p-value $\leq 0.05$ was considered as statistically significant.

\section{RESULTS}

A total of 27 patients with FA underwent allogeneic bone marrow transplant during this period. Twenty-four patients had congenital structural anomalies while 3 were phenotypically normal (table-I). All donors were screened for fanconi anemia and were found negative.

All patients had fully HLA matched donor. Conditioning protocol, stem cell dose and other transplant details are given in table-II.

Table-I: Patient demographics and disease characteristics.

\begin{tabular}{l|c}
\hline \multicolumn{2}{l}{$\mathbf{n}(\mathbf{\%})$} \\
\hline Gender & $15(55.5)$ \\
Male & $12(44.5)$ \\
Female & $10.17 \pm 4.99$ \\
\hline Age at Diagnosis (years) & $2-20$ \\
\hline Mean age \\
Range \\
\hline Age at Time HSCT (years) & $12.12 \pm 5.16$ \\
Median & $4-25$ \\
Range & $19.80 \pm 12.28$ \\
\hline Waiting time for HSCT (months) & $3(11 \%)$ \\
\hline Physical Features & $24(89 \%)$ \\
No physical abnormity & $16(66 \%)$ \\
Physical abnormality present & $17(70.8 \%)$ \\
Short stature & $7(29 \%)$ \\
Fanconi facies & $4(16.6 \%)$ \\
Skeletal malformation &
\end{tabular}

\section{Post-Transplant Complications}

Major post-transplant complications were febrile neutropenia in 26 (96\%), cyclosporine induced hypertension in $18(66.6 \%)$, mucositis grade II-III in 12 (44.4\%), renal impairment in 8 (29.6\%), gut toxicity II-IV in $7(25.9 \%)$ and haemorrhagic cystitis in $5(18.5 \%)$ patients. Acute GVHD IIIV was seen in $4(14.8 \%)$ patients involving skin and gut. Chronic Graft versus Host Disease was found in 7 (26\%) patients. Out of these 7, three $(42.8 \%)$ had extensive disease affecting skin, liver, gut and lungs while 4 (57.2\%) had limited chronic GVHD of skin.

\section{Transplant Related Mortality}

Five $(18.5 \%)$ patients died in early post-transplant period, 3 had primary graft failure (PGF), one had diffused alveolar haemorrhage and 1 patient died due to grade IV gut toxicity. Seven (25.95\%) patients died later after discharge from transplant ward. Mortality due to other complications were respiratory infections $(n=4)$, grade IV gut GVHD $(n=1)$, multi-system refractory CMV disease $(n=1)$ and one patient died of secondary acute myeloid leukaemia 4.5 years after HSCT.

Table-II: Transplant details.

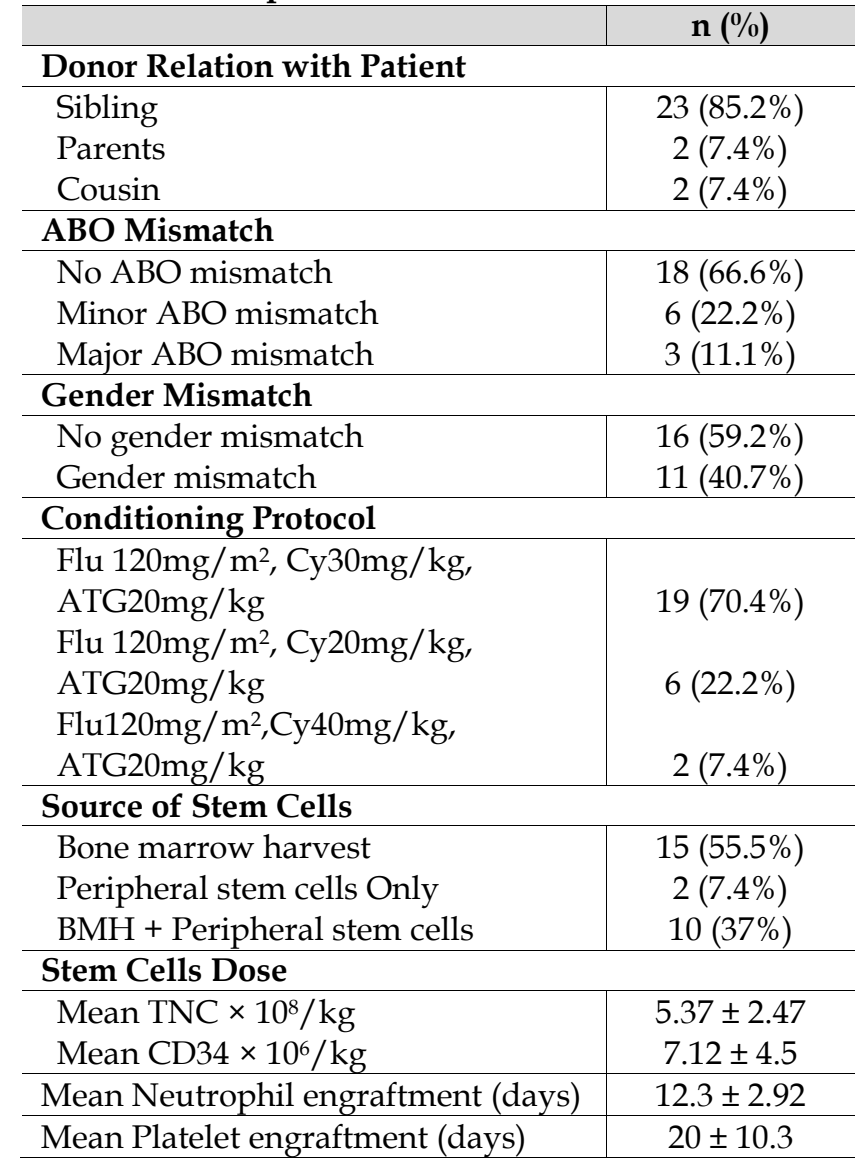

\section{Overall Survival}

Overall survival (OS) after allogeneic bone marrow transplant at 6 months was $67 \%$ which dropped to $63 \%$ at 12 months. OS at 5 and 8 years 
was 59\% and 55\% respectively. Overall Survival with Cyclophosphamide at $30 \mathrm{mg} / \mathrm{kg}$ was $62 \%$ in comparison to $33 \%$ and $50 \%$ with Cy $20 \mathrm{mg} / \mathrm{kg}$ and Cy $40 \mathrm{mg} / \mathrm{kg}$ respectively. Although the total number of patients was very small in other two groups, 6 patients in Cy20mg/Kg and 2 in Cy40 $\mathrm{mg} / \mathrm{Kg}$. Multivariate analysis demonstrated that

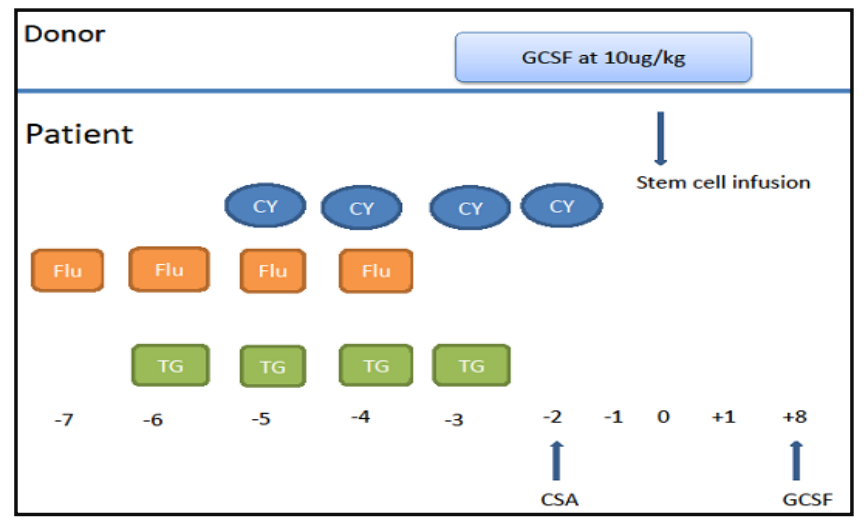

Figure-1: Conditioning regimen for Fanconi Anemia patients. CY; Cyclophosphamide, Flu; Fludarabine, TG; Thymoglobulin, G-CSF; granulocyte colony stimulating factor, CSA; cyclosporine.

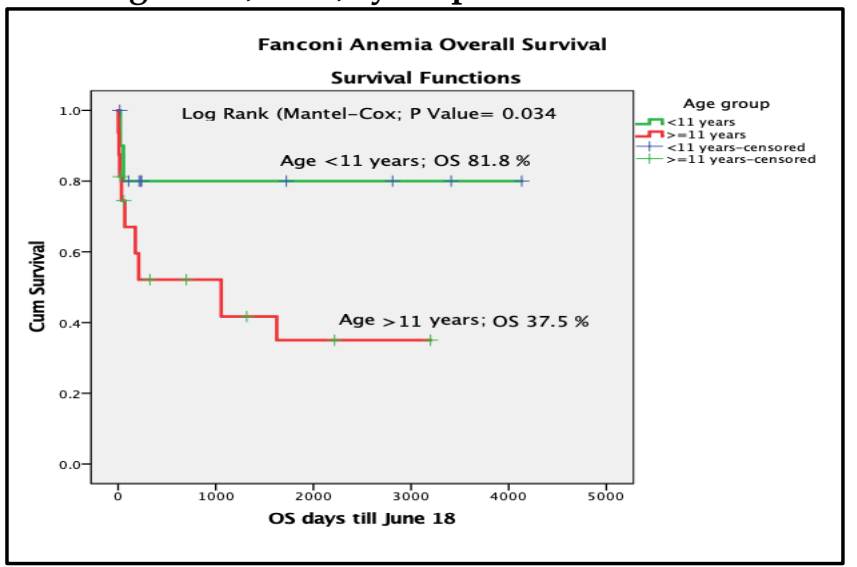

Figure-2: Kaplan Meier survival curve in relation to age of patients at HSCT.

patients who had transplant at younger age of less than 11 years had statistically significant superior outcome (fig-2). Patients who developed acute GVHD had inferior outcome (OS 52\%) in comparison to those without GVHD (OS 78\%), but this was not statistically significant ( $p$-value 0.06). Statistically significant association was not observed when overall survival was compared with disparity in blood group or gender, waiting time for transplant and stem cell source.

\section{DISCUSSION}

Our study evaluated 27 fanconi anemia patients who underwent allogeneic HSCT in the last 18 years at AFBMTC. Thisis the largest group reported from Pakistan and provides an opportunity to analyze the outcome of HSCT practice in this rare disease. We observed congenital anomalies and malformations in $89 \%$ patients, which is close to reported frequency of $79 \%$ by Roa et al ${ }^{14}$.

We transplanted all patients with fully HLA matched donor. Literature review showed survival advantage in HLA matched sibling transplants over haplo-identical or matched un-related HSCT $^{15}$. Chances of finding HLA matched sibling in our population is high in comparison to western countries due to large family size and high proportion of consanguineous marriages ${ }^{16}$. Mehta et al observed improved outcome (OS $80 \%$ at 1 and 3 years post-HSCT) with haploidentical and matched unrelated donor transplants in fanconi anemia ${ }^{17}$. We hope that in near future we will be able to offer haploidentical transplant to those patient who do not have fully matched family donor.

We used irradiation free, fludarabine-based preparative regimen with thymoglobulin and low dose cyclophosphamide. Benajiba et al reported improved engraftment $(100 \%)$, less conditioning toxicity (grade II mucositis in 5\%), decreased incidence of both acute GVHD (15\%) and chronic GVHD (10\%) with better long term survival $(95 \%)$ with this protocol ${ }^{15}$. However our results are in contrast to those reported by Benajiba, as we observed primary graft failure followed by infectious complication along with conditioning toxicity (gut toxicity $25.9 \%$, mucositis $44.4 \%$ ) and high early post-transplant mortality $(18.5 \%)$.

In this study we used bone marrow harvest as primary source of stem cells for almost all patients and resorted to peripheral stem cells collection for completion of stem cells dose. Only two patients received peripheral stem cells. We observed no correlation with increased risk of GVHD and source of stem cells likely due to less number of patients receiving peripherals stem 
cells. Kumar et al reported an increased risk of chronic Graft Versus Host Disease (31\% vs 17\%) when peripheral blood was used as source of stemcells, emphasizing the importance of considering marrow as the source of stem cells in FA patients as these patients are already at high risk of GVHD and secondary malignancies ${ }^{18}$.

Our patients had neutrophil and platelet engraftment at 12 and 20 days respectively. Similar results (neutrophil engraftment at 13 days, platelet engraftment at 20 days) were reported by Ayas from King Faisal Specialist Hospital and Research Center (KFSHRC) in KSA ${ }^{19}$.

In our study 11 (40.8\%) patients had Graft versus host disease. More patients had chronic GVHD involving skin, gut, liver and lungs as compared to acute GVHD (26\% Vs $14.8 \%$ ). Although there is improvement in HLA typing in recent times but the incidence of GVHD has not decreased in patients with FA, contributing to high morbidity and mortality. Guardiola et al reported high incidence of GVHD in FA patients as compared to similar cohort of Aplastic anemia patients (Cumulative incidence of grades II-IV Acute GVHD in patients $\leq 12$ years of age was $72 \%$ in FA versus $13 \%$ in non-FA patients) ${ }^{20}$. Patients in our study who developed GVHD had inferior overall survival (78\% vs $52 \%, p$-value 0.06). European Blood and Marrow Transplantation (EBMT) group also reported GVHD as the leading cause of post-transplant mortality in FA (35\%) followed by infections (27\%) and secondary malignancy $(10 \%)^{21}$.

Major factors contributing to mortality in our study were primary graft failure, conditioning toxicity, opportunistic infections and GVHD. Macmillan et al reported opportunistic infections $(13 \%)$ and conditioning toxicity $(10 \%)$ as leading cause of death ${ }^{22}$. One patient in our study died due to secondary malignancy (Acute Myeloid leukemia) at four years post BMT. The long-term overall survival in fanconi anemia post-transplant patients is a dversely affected by secondary malignancies especially solid tumors ${ }^{8}$. To fully ascertain long term risk of malignancy, our cohort of patients need long term follow-up.

We observed superior post-transplant outcome and better long-term overall survival (OS) in patients who were transplanted before the age of 11 years $(81.8 \%$ vs $37.5 \%$ with $p$-value $<0.03)$. Mehta et al reported excellent outcomes when HSCT was performed before 10 years of age (OS $92.3 \%$ in $<10$ years vs $63.2 \%$ in $>10$ years; $p<0.02$ )

17. Ayas et al demonstrated poor post-transplant outcome at older age (OS $78 \%$ in $\leq 14$ years of age versus $34 \%$ in $\geq 14$ years, $p<0.001$ ) and in FA patients with myelodysplastic or leukemic transformation (5 years OS 67\% versus $43 \%, p<0.03)^{23}$. We transplanted all patients in aplastic phase without any features of MDS or acute leukemia. So we cannot comment on poor outcome of those with MDS or leukemia. Thus in this study the only statistically significant difference with superior outcome was early age at time of trans-plant.

\section{LIMITATION OF STUDY}

Limitations of study are small cohort of patients, retrospective nature of study, lack of genetic mutation analysis and changes in supportive care during the study period. Since Fanconi anemia is a rare disorder so the number of cases at one particular center will always remain low. In order to formulate better HSCT strategy, there is need to have a greater number of patients. It is suggested that all centers in Pakistan offering bone marrow transplant analyze their data together under unified transplant registry.

\section{Disclosure}

Abstract of this study was presented as free paper at Pakistan Society of Hematology (PSH) conference held at Aga Khan University Hospital Karachi in March 2019. It was also displayed as poster at $45^{\text {th }}$ Annual Meeting of the European Society for Blood and Marrow Transplantation (EBMT).

\section{CONCLUSION}

We observed significant survival difference in Fanconi anaemia patients when they were transplanted at younger age of less than 11 years. 
Moreover low dose Cyclophosphamide at $30 \mathrm{mg}$ / kg with Thymoglobulin 10mg/kg and Fludarabine $120 \mathrm{mg} / \mathrm{m}^{2}$ was well tolerated and acceptable conditioning protocol. GVHD adverse-ly affected long term survival necessitating better preventive and treatment strategies. Long-term follow-up is mandatoryin these patients due to increased risk of malignancy.

\section{CONFLICT OF INTEREST}

This study has no conflict of interest to be declared by any author.

\section{REFERENCES}

1. Dong H, Nebert DW, Bruford EA, Thompson DC, Joenje H, Vasiliou V. Update of the human and mouse Fanconi anemia genes. Hum Genomics 2015; 9(1): 32.

2. Rosenberg PS, Tamary H, Alter BP. How high are carrier frequencies of rare recessive syndromes? Contemporary estimates for Fanconi Anemia in the United States and Israel. Am J Med Genet A 2011; 155A(8): 1877-83.

3. Callén E, Casado JA, Tischkowitz MD, Bueren JA, Creus A, Marcos R, et al. A common founder mutation in FANCA underlies the world's highest prevalence of Fanconi anemia in Gypsy families from Spain. Blood 2005; 105(5): 1946-49.

4. Cheung RS, Taniguchi T. Recent insights into the molecular basis of Fanconi anemia: genes, modifiers, and drivers. Int J Hematol 2017; 106(3): 335-44.

5. Savage SA, Walsh MF. Myelodysplastic syndrome, acute myeloid leukemia, and cancer surveillance in Fanconi anemia. Hematol Oncol Clin North Am 2018; 32(4): 657-68.

6. Kutler DI, Singh B, Satagopan J, Batish SD, Berwick M, Giampietro PF et al. A 20-year perspective on the International Fanconi Anemia Registry (IFAR). Blood 2003; 101(4): 1249-56.

7. Savage SA, Dufour C. Classical inherited bone marrow failure syndromes with high risk for myelodysplastic syndrome and acute myelogenous leukemia. Semin Hematol 2017; 54(2): 10514.

8. Bonfim C, Ribeiro L, Nichele S, Bitencourt M, Loth G, Koliski A, et al. Long-term survival, organ function, and malignancy after hematopoietic stem cell transplantation for Fanconi anemia. Biol Blood Marrow Transplant 2016; 22(7): 1257-63.

9. Pinto FO, Leblanc T, Chamousset D, Le Roux G, Brethon B, Cassinat B, et al. Diagnosis of Fanconi anemia in patients with bone marrow failure. Haematologica 2009; 94(4): 487-95.

10. Paustian L, Chao MM, Hanenberg H, Schindler D, Neitzel H, Kratz CP, et al. Androgen therapy in Fanconi anemia: a retrospective analysis of 30 years in Germany. Pediatr Hematol
Oncol 2016; 33(1): 5-12.

11. Ebens CL, MacMillan ML, Wagner JE. Hematopoietic cell transplantation in Fanconi anemia: current evidence, challenges and recommendations. Expert Rev Hematol 2017; 10(1): 81-97.

12. Przepiorka D, Weisdorf D, Martin P, Klingemann HG, Beatty P, Hows J, et al. Consensus conference on acute GVHD grading. Bone Marrow Transplant 1995; 15(6): 825-28.

13. Jagasia MH, Greinix HT, Arora M, Williams KM, Wolff $\mathrm{D}$, Cowen EW, et al. National institutes of health consensus development project on criteria for clinical trials in chronic graftversus-host disease: I. the 2014 diagnosis and staging working group report. Biol Blood Marrow Transplant 2015; 21(3): 389401.

14. Fiesco-Roa MO, Giri N, McReynolds LJ, Best AF, Alter BP. Genotype-phenotype associations in Fanconi anemia: A literature review. Blood Rev 2019: 100589.

15. Benajiba L, Salvado C, Dalle JH, Jubert C, Galambrun C, Soulier $\mathrm{J}$, et al. HLA-matched related-donor HSCT in Fanconi anemia patients conditioned with cyclophosphamide and fludarabine. Blood 2015; 125(2): 417-18.

16. Shamsi TS, Hashmi K, Adil S, Ahmad P, Irfan M, Raza S, et al. The stem cell transplant program in Pakistan - the first decade. Bon Marrow Transplant 2008; 42(S1): S114-17.

17. Mehta PA, Davies SM, Leemhuis T, Myers K, Kernan NA, Prockop SE, et al. Radiation-free, alternative-donor HCT for Fanconi anemia patients: results from a prospective multiinstitutional study. Blood 2017; 129(16): 2308-15.

18. Kumar R, Kimura F, Ahn KW, Hu ZH, Kuwatsuka Y, Klein JP, et al. Comparing outcomes with bone marrow or peripheral blood stem cells as graft source for matched sibling transplants in severe aplastic anemia across different economic regions. Biol Blood Marrow Transplant 2016; 22(5): 932-40.

19. Ayas M. Hematopoietic cell transplantation in Fanconi Anemia and dyskeratosis congenita: A minireview. Hematol Oncol Stem Cell Ther 2017; 10(4): 285-59.

20. Guardiola P, Socié G, Li X, Ribaud P, Devergie A, Espérou H, et al. Acute graft-versus-host disease in patients with Fanconi anemia or acquired aplastic anemia undergoing bone marrow transplantation from HLA-identical sibling donors: risk factors and influence on outcome. Blood 2004; 103(1): 73-77.

21. De Latour RP, Porcher R, Dalle JH, Aljurf M, Korthof ET, Svahn $\mathrm{J}$, et al. Allogeneic hematopoietic stem cell transplantation in Fanconi anemia: the European Group for Blood and Marrow Transplantation experience. Blood 2013; 122(26): 4279-86.

22. MacMillan ML, DeFor TE, Young JA, Dusenbery KE, Blazar BR, Slungaard A. Alternative donor hematopoietic cell transplantation for Fanconi anemia. Blood 2015; 125(24): 3798-804.

23. Ayas M, Saber W, Davies SM, Harris RE, Hale GA, Socie G, et al. Allogeneic hematopoietic cell transplantation for fanconi anemia in patients with pretransplantation cytogenetic abnormalities, myelodysplastic syndrome, or acute leukemia. J Clin Oncol 2013; 31(13): 1669. 